\title{
A Pedagogical Framework for Web-Based Autonomous English Learning in Chinese Context from the Perspective of Eco-Constructivism
}

\author{
Dali Ning \\ School of English and Education, Guangdong University of Foreign Studies, Guangzhou, China \\ Email:200411216@oamail.gdufs.edu.cn
}

Received 4 January 2015; accepted 11 August 2015; published 14 August 2015

Copyright (C) 2015 by author and Scientific Research Publishing Inc.

This work is licensed under the Creative Commons Attribution International License (CC BY). http://creativecommons.org/licenses/by/4.0/

(c) (i) Open Access

\begin{abstract}
The application of web-based autonomous English learning (WAEL) in China has shown serious problems in recent years. Combining language ecology theory and constructivism, this paper proposes a pedagogical framework guided by eco-constructivism. It then gives advice from perspectives of curriculum design, its operation and evaluation, and shares the successful experience of learning community construction and formative evaluation operation in Guangdong University of Foreign Studies. The writer hopes that this research will shed light on the construction of a sustainable development of WAEL in China and e-teaching in context worldwide.
\end{abstract}

\section{Keywords}

Web-Based Autonomous English Learning, Eco-Constructivism, Learning Community, Formative Evaluation

\section{Problems Discovered in Online Classroom English Learning in Chinese Context}

The rapid development of technology and the increasing popularity with network in this information age has made teaching and learning conducted in ways never before available. In the past 20 years, a web-based learning system has been widely used in higher education (Kim \& Bonk, 2006). As a result, blended learning, the synthesis designed to incorporate e-learning with face-to-face learning was gradually adopted worldwide. In China, blended English learning is composed of two parts, traditional classroom learning (the face-to face part) and web-based autonomous English learning (WAEL) (the online part). The latter aims to cultivate students' learn- 
ing autonomy to construct language knowledge and enhance their English proficiency by making full use of the resources on line.

Researches (Xu, 2006; Yang, 2006; Gong, 2006; Fu \& Yang, 2007; Wang, 2008; Zhang, 2009, etc.) into the learning students' satisfaction and learning efficiency of this new teaching model has gained positive results: most students are content with the rich resources provided online as means to facilitate their study and prefer this new teaching model to the old traditional one; students believe WAEL stimulates their learning motivation, improves their autonomous learning ability and enhances their learning confidence; compared with traditional classroom learning, WAEL shows an advantage in producing better English learning outcome.

Meanwhile, problems are found during the implementation of WAEL. Xu (2006) points out that WAEL helps more in the improvement of receptive knowledge (such as listening and reading) than productive knowledge (such as speaking and writing), since most of the exercises are objective (such as multiple choices questions and blank filling, etc.). Fu, Yang, (2007) and Zhang (2009) argue that the new model turns to be effective in listening and reading thanks to the abundant resources on line which allows students to practice and repractice with whatever material they select, but not quite helpful in speaking due to lack of evaluation software and supervision in testing oral practice.

Researchers who focus their attention on student's adaptability find that the previous research results are too optimistic. It's just a psychological tendency and cannot reflect the whole landscape. According to their research, (Sun, 2007; He, 2007; Liu, 2009, 2012; Zhong, 2012; Zhang, 2012, etc.), a large number of students in WAEL show poor adaptation to it: they show poor self-control during study; many play games, chat, or watch movies during class; some cannot distinguish useful information from useless resource; some do not know how to seek help from peer learners through network, let alone take an active part in discussion. Liu (2009) in her research discovers that of $66 \%$ online learners (students who get on line for other purposes are not included) regard WAEL as "very important” but display very poor ability in autonomous learning. There are only 56\% of students who will not engage in other things that has nothing to do with study. Though 75\% of students agree that the online environment and resources help to improve their pronunciation, few would make full use of it. Apparently, there is large gap between students' behavior and their recognition. This poor adaptability of learners results in poor learning performance and thus frustrates their learning activeness, which in turn lead to ever poorer adaptability. Before situation gets worse, it is urgent to figure out a framework or theory that can lead WAEL back to the right track.

\section{WAEL, Constructivism and Social Constructivism}

The characteristics of WAEL, in many respects, are in line with constructivism theory. Hence, for years, researchers and language practitioners have adopted constructivism theory as the guidance for both research and teaching practice (He, 1997; Ding, 2005; Wang, 2008; Shi, 2012, etc.). Constructivism maintains that learning is a personal interpretation of the world. Learners construct or at least interpret their own reality based on their perception of experiences. An individual's knowledge is a function of his or her experiences, mental structures, and beliefs that are used to interpret objects and events (Jonassen, 1991). Therefore, learning process is one that connects what one is to know with what one has previously learned. Alonso (2005) in his paper points out that "the most useful tools for the constructivist designer is hypertext and hypermedia because it allows a branched design rather a linear format of instruction”. Hypertext and hypermedia are widely used in WAEL as knowledge input in forms of words, picture, audio or video clip. They stress the connection between upper and lower branches in that every lower branch is based on the upper one. The lower branch connects previously learnt knowledge and extends to the new unknown experience. And the learner who fails to extend his knowledge to a new stage can still go back to what is known and comfortable with until he or she is ready to move to the next phase.

When constructivism theory was developed into socialist constructivism where collaborative work and relationships between learners, their peers and teachers in the social environment were taken into account, constructivist theory tends to be an ecological concept. According to social constructivism, the construction of knowledge cannot be achieved without cooperation with other people. The learning process has to be adjusted from time to time and is influenced by various social cultural factors then. In other words, learning is a process of cultural participation. It is only when the learners participate in learning activities with some cultural support, are they able to internalize knowledge through cooperation and construct knowledge for each other. Palloff and Pratt (1999) stated that "in the online classroom, it is the relationships and interactions among people through 
which knowledge is primarily generated”. They suggest that learning community is an essential tool for elearning where there is interaction between students, text and teacher, cooperative learning done through peer comments and exchange of ideas, as well as social meaning construction through discussion, query and debate. The process of knowledge construction requires interaction not only between individual and the physical environment but also within the social environment which is formed by learning community. The stress on the important role of interaction between learners, the connection between subjects within the environment is quite in line with principles proposed by ecological language education.

\section{WAEL and Ecological Language Education}

In the early 1970s, Lawrence Gremin proposed a concept named "educational ecology", an attempt to analyze phenomenon and problems in education by applying theories and methods in the field of ecology. The adoption of the ecological concept in education brings a new perspective to language teaching. Educational ecology suggests that educational ecosystem is a dynamic interplay of multiple factors, including learning environment (from both macro and micro perspectives, such as society, the political, economic, and cultural factors, school, classroom, family, community, and individual, etc.), that influence the environment and the subjects (teachers and students). So far, most of the researches are conducted from micro perspective since elements from macro perspective are so diversified and changeable that measurement seems virtually impossible.

Some researchers transfer the ecological principles to language study. Einar Haugen defined the "language ecology" as "the study of interrelations between any given language and its environment" (Haugen, 1972: 325). Researches on ecological education didn't start in China until the early twenty-first century. Gu (2005) maintains that internet brings three innovations to educational development: breaking the restriction that campus ecosystem imposes on students, turning restrictions into opportunities; bringing resource equity to people in different natural environment; realizing the ideal of "teaching regardless of social distinctions" proposed by Confucius, the greatest Chinese educator in ancient times.

WAEL, when viewed from an ecological perspective, is an ecosystem made up of students, teachers, web system and teaching material, etc. The process of learning is the ecological interaction between all components in the learning ecosystem. Through internet and multimedia technology, WAEL extends English learning from campus ecological environment to virtual ecological environment where factors such as learning system, learning resources, learning community and teachers are interwoven. Among these interactive factors, there is cooperation (in forms of consultation, tutoring, discussion, etc.) among learners and between learners and teacher, which is an essential for the improvement of learning efficiency.

According to Gremin (1976), the concept of ecology is useful in that it emphasizes inter-relationship. From the ecological perspective, language is a system of relations rather than a collection of objects. It mediates relationships between people and the world (Van lier, 2004). Language learning environment is a complex adaptive system, of the mind as the totality of relationships between developing person and the surrounding world, and learning is the result of meaningful activity in an accessible environment (Van Lier, 1997). All the factors and elements in the learning environment somehow restrict and mean while rely on each other for survival and development and the change of every single factor may lead to the change of learning environment and therefore result in the change of learning outcome. It is essential that the design of learning carefully maintain a balance between all elements so as to ensure a sustainable development of the whole ecosystem.

Is this ecological concept depriving the guiding role of constructivism theory in WAEL? How could we find a better framework to facilitate teaching and learning on WAEL and to ensure it to develop in a scientific and sustainable way?

\section{Eco-Constructivism, a Combined Theory of Constructivism and Language Ecology}

Complexity theory seems to be the best choice so far when it comes to deal complex SLA learning situations, i.e. WAEL, exchangeable terms are computer assisted language learning (CALL), blended learning, etc. CALL is rather complicated in that it can be opportunities for language practice, for comprehensible input and interaction, or for the expansion of learners' experience with community where target language is spoken and to connect them with others who engage in such practices as code switching (Thorne \& Black, 2007). As Larsen-Freeman and Gameron (2008) stated "Complexity theory aims to account for how the interacting parts of a complex sys- 
tem give rise to the system's collective behavior and how such a system simultaneously interacts with its environment”.

Apparently, constructivist theory shares principles with ecological concept for both highlight the connection between elements. However, they differ in their focuses. The former offers a detailed description of the meaning construction between and within learning subjects (such as learners and teachers), while the latter emphasizes the connection and balance between factors in the whole learning environment (system, resources, outside classroom factors, etc.). Both interpret how online learning takes place in certain environment, but with limited scope. Hence, the writer hereby proposes eco-constructivism, a combined theory of constructivism and language ecology to interpret the construction process of learners' knowledge building and to explain how factors in this WAEL ecosystem interact with each other.

\section{A Pedagogical Framework for WAEL from the Perspective of Eco-Constructivism}

Learners' satisfaction somehow reflects the effectiveness of a course. Researches have been conducted on the factors that affect learners' satisfaction with e-learning system. DeLone and McLean (1992, 2003) try to evaluate e-learning system satisfaction from information system designer's point of view. They propose three determinants: system quality, information quality and service quality. Information quality requires the information to be accurate, up to date, well-organized and effectively displayed. It includes convenience of access, system functionality, reliability, navigation ease and flexibility, etc. Laterintheir paper in 2013, Petter, DeLone and McLean add that the most noticeable predictors of system quality are the characteristics of the users of the system. The user's perception of the system quality may influence the user's technical capability and self-confidence. However, we may help them to feel comfortable with the system by changing their attitude through training. Service quality depends on responsible, reliable and technically competent staff for supportive system service. Wang (2003) argues that learner interface, content, and personalisation, and learning community are essential components of course design. Lee et al. (2007) list variables that are related to the operation of e-learning from learner's perspective. Lee et al. (2007) points out that a successful online course should be well-organized, learner controllable, and interactive. On top of that, it should be able to trigger learners' enthusiasm, get them fully involved in interactive learning activities .Combining the two models proposed by DeLone and McLean and Wang, Lu and Chiou (2010) identify four variables that determines the satisfaction of e-learning: interface friendliness, content richness, perceived flexibility and perceived community. The realization of the importance of learners' interaction and a harmonious relationship in the learning environment proves that online learning has somehow been viewed as an ecosystem with multicomponents.

Chen (2010) stated "there are two main principles to ensure a sound operation of SLA ecosystem: to stabilize teaching structure while incorporating all teaching elements and to foster individual development, leading it to the track of sustainable development." There are studies on the construction of framework for WAEL in Chinese context though not many. Li (2011) proposed a " $2+\mathrm{X}$ ” pattern for WAEL in which " 2 " refers to the WAEL and offline classroom learning. "X” includes online course, homework, exam, and assessment, etc, which all interact with each other and most importantly, interact with the center--web system. " $\mathrm{X}$ " can be updated anytime since studies in this field is still developing. In this framework, the assessment part is composed of teacher, computer and final exam. Learners are expected to assess their peers' work by using their computer. Compared with traditional exam assessment, the combination of exam and peer assessment better reflects the learning process of an individual and helps trigger their willingness to learn and cooperate. It also provides teachers with a fuller picture of students' performance, so as to better their role as a supervisor.

A more comprehensive framework is found by Shi (2012). According to Shi, web-based teaching design should be learner-centered. Knowledge construction is achieved through interaction between learners and learning environment. In the process of meaning construction three kinds of interactions take place: interaction between subjects (learner and teacher/facilitator); interaction between subject and tool (learner and computer); and interaction between subject and target (learner and resource). This theoretical framework is ecologically humane. It puts people rather than system to be the central role of learning process. All other elements that work in this ecological learning environment interact with each other and affect learning result through interaction. However, it does not give a descriptive account to w role learning community plays, which as discussed above, should be an essential determinant for the success of online learning. Moreover, it only gives the three types of linear relationships between learner and other elements, and leaves more complex and non-linear relationships untapped. 
The pedagogical framework proposed in this paper is based on eco-constructivism and the previous studies in this field. As WAEL is one of the two parts in blended learning in Chinese context, the pedagogical framework cannot offer a comprehensive landscape of the whole learning process without consideration of interaction between traditional face-to-face class and other elements in the ecosystem. The following framework (Figure 1) reveals the complexity of WAEL system and intends to demonstrate the more intricate inter-dependence among elements.

As is shown in the figure, the large circle is the ecosystem of WAEL with learner to be the center which closely interacts with other elements-system, online resources, traditional class, teacher and learning community.

Learning has been regarded as a complex and dynamic system (You, 1993; Branch, 1999). The learner coevolves with other elements of the system. WAEL aims to cultivate students from passive English learners to be active English participants in learning activities. This is a result of undergoing a dynamic, adaptive process of change as they interact with other elements in the multimodal learning environment (Wang, Han, \& Yang, 2015). Learner is the main initiator of all relationships in the ecosystem. Learner's learning attitude and ability to a large content, determines the successful operation of the whole course. However, not all of them are readily equipped with required techniques when they take WAEL course at the beginning. Learners, before successfully transformed into active learners need to be trained of learning strategies, the knowledge of technological tools, collaborative skills and metarecognition ability that help them become better adapted to WAEL

Online system serves as technical support for the whole ecosystem. A stable, accessible, leaner controllable system enhances learning efficiency and stabilizes learning involvement. Contrarily, if the system always breaks down or runs slowly, or, if the navigation is not scientifically designed, learners will gradually lose interest in learning, or worse, quit from WAEL, which as is found in some of the researches, has already happened in some universities.

Information resources provided by the system is the major knowledge input. It is the new knowledge that learners need for meaning construction. Taking advantage of multimedia technology, resources can be presented in forms of text, audio, video or hypertext to attract learners' attention and turn learning process into a pleasant journey of recognition. It is important that exercises between and within units should be coherent and consistent so that learners' knowledge construction is systematic. It is suggested that learning content should be personalized so as to meet different learning needs. Moreover, facing such huge amount of online resources, learners should be trained to distinguish whether the information helps in their study so as not to "overuse", "misuse" or "underuse" the resources.

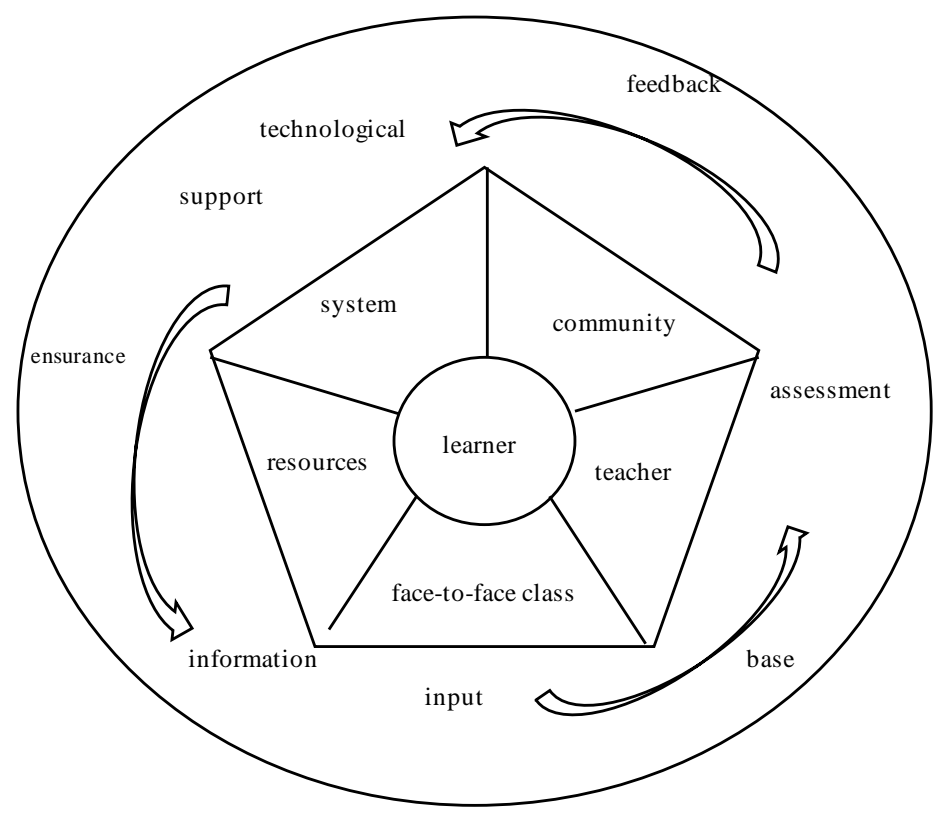

Figure 1. Eco-constructivist framework for WAEL. 
In most of the universities nowadays in China, college English teaching is a combination of face-to-face classroom teaching and online classroom teaching. Traditional class is part of the resource where the learners' learning experience comes from. The learners transform the recognition they acquired in traditional class into existing experience and then combine it with the information resources they meet in online class to construct new knowledge through cooperation between learners and teachers or in the learning community.

Cooperation is the essential way through which knowledge construction is achieved. It happens among learners and between teacher and students in online learning community. This is the place where difficult questions are discussed, knowledge and experience are shared. Assessment is made not only from teacher but from peers as well. Teacher, who used to be "knowledge transferor, class controller" now becomes facilitator, advisor and promoter of learning. In the forum of online learning community, feedbacks are made not only about students' learning but on teaching and even online system as well. It is reference for future adjustment.

\section{Important Elements That Affect WAEL}

To ensure that each class goes on smoothly, WAEL course design should pay special attention to teaching material, learning community and course assessment, which are in correspondence with three steps of teaching: before class, during class and after class.

Curriculum design is crucial for maintaining ecological balance in WAEL. It directly affects the connection between old knowledge and new knowledge and hence learners' knowledge construction. The first step to design a curriculum is to select proper teaching material. Knowledge is the information input one acquires from the outside world. It is the result of thinking activities and meaning construction achieved through interaction between people. Accordingly, content, learner recognition and cooperative interaction are factors that need to be taken into consideration when curriculum is designed.

Cai (2011) points out that textbook should be content-based. Foreign language teaching should be a combination of language and professional knowledge. Textbook for English and non-English majors should bear different focuses. So are those for different learning stages (primary school, high school, college). Topics and content should be arranged at appropriate level. If the topics are too rarely discussed, or too difficult to understand, new information cannot connect with the previous experience that learners have acquired, which may lead to low efficiency in knowledge construction. If the topics are over discussed or the exercises are too easy, new information may overlap learners' pervious knowledge, which may lower down their learning interest and lead to low learning efficiency, too.

From recognitive perspective, the content of teaching material should be consistent so as to help learners construct knowledge schemas which is crucial for effective comprehension and thinking. In social life, one cannot avoid using multimodal ways of communication: language, picture, audio, video, etc. The combination of multimodal means reinforces, compliments and cooperates with discourses. It not only helps understanding but deepens recognitive memory as well. Therefore, WAEL, which aims to establish a realistic learning environment for learners to help them with knowledge construction, should select materials that are combinations of different modals of resources.

On the "national college English teaching seminar" in August 2014, a new teaching idea was proposed-_to put input as the basis and output as the driven force of learning”. On the conference, Shijian asserted that when there is sufficient language input, either it is from the teacher or gained by students themselves, with output to be the ultimate purpose, students' learning autonomy will be fairly motivated. Students will keep reflecting on what they have learned. As a result, a good language learning habit will be formed. He Lianzhen in her lecture said that language out put experience can turn a learner into an active language input processor for one learner's output may serve as the input for the rest of the others. Therefore, for the design of WAEL textbook, sufficient input is needed before exercises. It is hoped that learners can improve their leaning efficiency through "use what have just learned” method. Meanwhile, complementary learning resources are needed which differ in levels and styles so that learners will not feel bored and be able to select the exercises that suit their level. Thus, a personalized "learner autonomy" is achieved.

As we can see from previous researches, learning community is always listed as an essential determinant for a successful online course. Tang (1999) compares the competitive learning strategy adopted by Chinese students and the cooperative learning strategy adopted by American students. Research results show that American students prefer cooperative learning while Chinese students prefer competitive learning. Competitive learners put individual achievements in the first place. They always seek feedback or help from the most knowledgeable 
person (for example, teacher), and are unwilling to cooperate. However, in the virtual online forum, competitive learners are actively involved in discussion because this is the major source of information and feedback. Activities designed for the construction of social environment is the scaffolding of cooperative learning (Alonso, 2005). Many other researches (Harasimetal, 1995; Hutchins, 2001; Arbaugh, 2005; Monguet et al., 2006, etc.) show that participation in online forum helps enhancement of learning outcome. Online forum servers another function as well: it is the extension of traditional face-to-face class. What has not been fully studied due to time limit in traditional class can be continuously discussed in the online forum of WAEL.

Though most of WAEL in Chinese universities provide online learning community where teachers and learners can share information, solve problems, give feedback or comment, researches find poor involvement there. Investigations conducted by Gao, Gu (2005) and Lu, Gu (2006) on online education find that a large number of college students are unwilling to participate in learning community. One of the reasons, as is shown in the survey results, is the poor quality of online forum: "The online materials is a mixture of quality. There are a lot of nonsense talks and boring stuff”. To solve this problem, rules should be set up to guarantee the quality of shared materials online and correct use of learning community. Of course, the major reason that leads to unsuccessful learning community is the learning subject, students themselves. On the one hand, some have not formed the habit of "autonomous learning" yet. Some even fail to finish the assigned tasks on time. "In practice, many students treat WAEL with a passive attitude. They play games, music or watch films. Some leave after turning on the computer” (Zhang, 2009: 102). On the other hand, students fail to realize how important participation in online discussion is to the improvement of English learning and how an irreplaceable role learning community plays in their knowledge construction. Under such circumstances, learning atmosphere is destroyed; those who were passionate participants gradually lose their learning enthusiasm; the whole learning ecosystem gets into a catastrophically degrading cycle. Therefore, at the very beginning of the course, as the guide and facilitator, teacher need to give a very detailed account to the function and use of online learning community so as to guide them into active participation in it. This is a hard but very essential task. On top of that, cooperative opportunities need to be provided so that students, while receive and construct knowledge of their own, become information processor to help others' knowledge construction. In the year 2013 Guangdong University of Foreign Studies invented a concept of "learning coins" for WAEL and initiated a trial practice: students will be awarded a certain amount of "learning coins" after their participation in discussion, peer grading, peer comment or uploading useful learning materials; they can also gain "learning coins" by asking questions or providing answers in learning community about the difficulties they come across during learning. The poster that is viewed by quite a number of people will be awarded with extra "learning coins". "Learning coins" functions as virtual money on line. They can be used to download materials or buy other services. The amount of "learning coins" a student processes is an authentic reflection of how active one participates in learning. It is an important indicator for the assessment of students' performance, convenient and easy to count for teachers. According to the teachers, after the application of this new method, they have witnessed much more active involvement from students in online learning community.

Teaching assessment is an important way for teachers to obtain teaching feedback, improve teaching management, and ensure teaching quality. It is also evidence upon which students adjust their learning strategy and enhance learning efficiency (Wu, 2008). Compared with terminal assessment which merely focuses on the learning result, formative assessment stresses on the learning progress and can more scientifically reflect many language prospects of a learner, such as motive, change of attitude, autonomous learning ability, cooperative learning ability, learning strategy and cross-cultural awareness, etc. Formative assessment is composed of teacher assessment, peer assessment and self-assessment. Doubtlessly, formative assessment is a very good choice for WAEL management. Through their empirical study, Zhou, Qin (2005) discover that formative assessment helps trigger students' learning motive and interest; provides detailed account of what and how students have achieved and make it possible for self-supervision. Meanwhile, students' competence in autonomous learning, cooperation and interpersonal communication are cultivated.

Guangdong University of Foreign Studies is one of first universities that initiated formative assessment inWAEL. At the beginning of a semester, every student is required to set up a e-portfolio where every learning behavior and achievement of the learner is demonstrated, including time online(time of logging in and out, length of learning), homework, face-to-face talk with teacher, feedback, involvement in learning community, self-assessment, peer-grading, peer-assessment, etc. The application of "learning coins" enables teachers to get a clear picture of dynamic development of students' learning ability and involvement in the course as well. 
"Learning coins” is a game like study style. It removes the boring feeling of learning and activates participation in cooperation. In order to gain "learning coins", students need to ask questions, involve in discussions, grade other learners' work, and make self assessment. It is through this process that they achieve two roles in WAEL_- “consumer” and "producer”: they produce knowledge while they are consuming it. Through the whole learning process of discussion, comparison and assessment, the ability of metarecognition is enhanced, which, in turn, will promote meaning construction. Therefore, formative assessment achieves not only the goal of "assessment for learning” but also the ideal of "learning while assessing”. This is how the ecosystem of WAEL develops in a healthy, sustainable way.

\section{Conclusion}

WAEL has not gone through a long time in China. It is still at the exploring stage. The proposal of eco-constructivism aims to remind us that while we are developing and investigating the meaning construction of a foreign language, we need to respect the balanced development of the elements in this environment, without one of which WAEL cannot be successful. To sum up, WAEL is an ecosystem, with an online system as its technological insurance, learning resource as its base of input, traditional class as its complement, learners and teachers as its major subject. The sound operation of this ecosystem requires a careful selection of learning materials, an active learning community, and a reasonably designed formative assessment. The writer hopes that this paper will shed some light on future online teaching and research both in China and in context worldwide.

\section{Fund}

This study is supported by the Joint Funds for Youths of Guangdong University of Foreign Studies (13s6).

\section{References}

Alonso, F., Lopez, G., Manrique, D., \& Vines, J. M. (2005). An Instructional Model for Web-Based E-Learning Education with a Blended Learning Process Approach. British Journal of Educational Technology, 36, 217-235. http://dx.doi.org/10.1111/j.1467-8535.2005.00454.x

Cai, J. G. (2011). Research on the Compiling Concept of College English Textbooks at a Turning Point Period. Foreign Language Research, 5, 5-10.

Chen, J. L. (2010). Intergration between Network and Foreign Language Class-A Study Based on College English Teaching Innovation. Shanghai: Shanghai Foreign Language Education Press.

DeLone, W. H., \& McLean, E. R. (1992). Information Systems Success: The Quest for the Dependent Variable. Information Systems Research, 3, 60-86. http://dx.doi.org/10.1287/isre.3.1.60

DeLone, W. H., \& McLean, E. R. (2003). The Delone and McLean Model of Information Systems Success: A Ten Year Update. Journal of Management Information Systems, 19, 9-30.

Gao, C. L., \& Gu, Y. G. (2005). Factors That Influence the Participation of Online Forum. Computer-Assisted Foreign Language Education, 3, 27-31.

Gremin, L. A. (1976). Public Education. Newyork: Basic Books.

Gu, Y. G. (2005). Educational Ecology Model and Web-Based Education. Computer-Assisted Foreign Language Education, 8, 3-8.

Haugen, E. (1972). The Ecology of Language. Standford, CA: Standford University Press.

Jonassen, D. H. (1991). Objectivism versus Constructivism: Do We Need a New Philosophical Paradigm? Educational Technology and Research and Development, 39, 5-14. http://dx.doi.org/10.1007/BF02296434

Kim, K. J., \& Bonk, C. J. (2006). The Future of Online Teaching and Learning in Higher Education: The Survey Says. Educause Quarterly, 29, 22-30.

Lee, Y. K., Tseng, S. P., Liu, F. J., \& Liu, S. C. (2007). Antecedents of Learner Satisfaction toward E-Learning. The Journal of American Academy of Business, 11, 161-168.

Lu, H. P., \& Chiou, M. J. (2010). The Impact of Individual Differences on E-Learning System Satisfaction: A Contingency Approach. British Journal of Educational Technology, 41, 307-323. http://dx.doi.org/10.1111/j.1467-8535.2009.00937.x

Lu, Y., \& Gu, Y. G. (2006). An Empirical Study on Web-Based Education Ecology. Computer-Assisted Foreign Language Education, 12, 17-24.

Palloff, R. M., \& Pratt, K. (1999). Building Learning Communities in Cyberspace: Effective Strategies for Online Classroom. 
Sanfrancisco, CA: Jossey-Bass

Sun, D. (2007). An Investigation on Adaptation of Web-Based Learning. China Educational Technology, 7, 75-77.

Tang, S. (1999). Cooperation or Competition: A Comparison of US and Chinese College Students. The Journal of Psychology, 133, 413-423. http://dx.doi.org/10.1080/00223989909599752

Thorne, S., \& Black, R. W. (2007). Language and Literacy Development in Computer-Mediated Contexts and Communities. Annual Review of Applied Linguistics, 27, 133-160. http://dx.doi.org/10.1017/s0267190508070074

Van Lier, L. (1997). Approaches to Observation in Classroom Research-Observation from an Ecological Perspective. TESOL Quarterly, 31, 783-787.

Wang, Y. P., Han, X. B., \& Yang, J. (2015). Revisiting the Blended Learning Literature: Using a Complex Adaptive Systems Framework. Educational Technology \& Society, 18, 380-393.

Wang, Y. S. (2003). Assessment of Learner Satisfaction with Asynchronous Electronic Learning Systems. Information \& Management, 41, 75-86. http://dx.doi.org/10.1016/S0378-7206(03)00028-4

Wu, X. L. (2008). A Summary of Researches on the Application of Formative Assessment in Foreign Language Teaching in Universities in China. Foreign Language World, 3, 91-96.

You, Y. (1993). What We Can Learn from Chaos Theory? An Alternative Approach to Instructional Systems Design. Educational Technology Research Development, 41, 17-32. http://dx.doi.org/10.1007/BF02297355

Zhang, G. J., Chen, H. M., \& Zhang, G. S. (2009). An Empirical Study on Cultivation of Autonomous Learning Ability through Multimedia. Journal of Anhui Agricultural University, 3, 100-103.

Zhou, P. D., \& Qin, X. B. (2005). Application of Formative Assessment in Web-Based College English Teaching. Computer-Assisted Foreign Language Education, 10, 9-14. 